BIOMEDICA

Vol. 9, Nos. 1 y $2-1989$

\title{
ESPOROTRICOSIS DIAGNOSTICADA POR EL LABORATORIO
}

\author{
NELLY ORDOÑEZ* , JEANNETTE CASTILLO*, ELIZABETH CASTAÑEDA*
}

\begin{abstract}
De 1976 a 1989 se han diagnosticado 40 casos de esporotricosis en el laboratorio de Micología del Instituto Nacional de Salud. La enfermedad se presentó en pacientes entre 4 y 52 años y tuvo predilección por el sexo masculino: 35 de $40(87,5 \%)$; las formas clínicas más frecuentes fueron la cutánea fija, 18 de $40(45 \%)$, y la linfocutánea, 17 de $40(42,5 \%)$, con localización mayor en miembros superiores, 18 de 40 (45\%). El diagnóstico se estableció por el aislamiento del Sporothrix schenckii en 35 de 38 pacientes $(92 \%)$; los otros dos pacientes se diagnosticaron empleando otras técnicas: inmunofluorescencia directa, intradermorreacción y aglutinación en tubo.
\end{abstract}

\section{INTRODUCCION}

La esporotricosis es una micosis de gran prevalencia en Colombia $(1,2)$, que compromete piel, tejido subcutáneo, linfáticos regionales (3) y que en forma menos frecuente se disemina a articulaciones, huesos, pulmones y meninges (4); su distribución es mundial en zonas tropicales, presentándose en todas las edades y afectando ambos sexos $(3,5)$. En la naturaleza el agente etiológico, Sporothrix schenckii, tiene como hábitat material vegetal y suelo, razón por la cual las personas que laboran con estos materiales tienen mayor riesgo de sufrir la entidad tanto que se ha denominado a la esporotricosis como la "enfermedad de los jardineros" $(3,5)$.

El $S$. schenckii es un hongo dimórfico térmico, encontrándose su fase miceliar infectante en la naturaleza $\left(25-28^{\circ} \mathrm{C}\right)$ y su fase de levadura parasitaria a $37^{\circ} \mathrm{C}$. Es un hongo de crecimiento fácil en los medios usuales de micología como el Sabouraud, por lo tanto el cultivo utilizado para fines diagnósticos da una positividad de más del $90 \%$, especialmente en las formas clínicas cutánea fija y linfocutánea (3). Otras técnicas de laboratorio muy útiles en el diagnóstico son la inmunofluorescencia directa $(6,7)$ y la intradermorreacción $(8,9)$. En algunas formas de presentación de la enfermedad como la articular, la pulmonar y la diseminada, la aglutinación en tubo presenta una buena sensibilidad; del $70 \%$ en la pulmonar y cerca del $100 \%$ en la diseminada, aunque en las formas de presentación más frecuentes como son la forma cutánea fija y linfocutánea su utilidad es limitada $(10,11)$. En este trabajo se analizan 40 casos de esporotricosis diagnosticadas en nuestro laboratorio en un período de 14 años (1976-1989).

\section{MATERIALES Y METODOS}

\section{Pacientes}

Todos los pacientes o muestras fueron remitidos al laboratorio de Micología del Instituto Nacional de Salud, para estudios de cuadros clínicos compatibles con esporotricosis. A cada paciente se le consignó en un formulario la edad, sexo, procedencia, ocupación, forma clínica, localización de la lesión, antecedentes traumáticos y tiempo de evolución de la enfermedad.

\section{Toma y procesamiento de las muestras}

De las lesiones cutáneas y linfocutáneas se obtuvieron pus y escamas; se procesaron, además, sangre, suero y líquido pleural.

El examen directo se realizó con $\mathrm{KOH}$ al 10\% (12) y mediante la técnica de inmunofluorescencia (IFD), utilizando como conjugado anticuerpos anti-S. schenckii obtenidos en conejo y marcados con isotiocianato de fluoresceína $(6,7)$.

Grupo de Microbiología INS. 
Se realizaron cultivos de las muestras clínicas, en medio de Sabouraud modificado (Mycosel, BBL), los medios fueron incubados a $27^{\circ} \mathrm{C}$ por 4 semanas revisándolos semanalmente; las colonias sospechosas fueron examinadas microscópicamente con azul de lactofeonol (12); aquellas colonias que presentaban morfología compatible con $S$. schenckii fueron resembradas en agar infusión cerebro-corazón (BHI, BBL) e incubadas a $37^{\circ} \mathrm{C}$ para obtener su reversión a la fase de levadura (12).

La intradermorreacción (IDR) fue investigada utilizando como antígeno esporotricina obtenida de la fase de levadura (8). La lectura se realizó a las 48 horas, considerándose positiva una induración mayor o igual a $5 \mathrm{~mm}$. La presencia de anticuerpos circulantes anti-S. schenckii se investigó por medio de la técnica de aglutinación en tubo, considerando positivo un título mayor o igual a 1:4.

\section{RESULTADOS}

\section{Pacientes}

Se diagnosticaron por el laboratorio 40 pacientes con esporotricosis; las edades oscilaron entre 4 y 52 años presentándose en mayor proporción en personas menores de 40 años, 32 pacientes ( $80 \%$ ). El sexo que predominó fue el masculino, 35 pacientes $(87,5 \%)$; la procedencia y la ocupación de los pacientes están consignadas en las Tablas 1 y 2 .

\section{TABLA 1}

Procedencia de los pacientes con Esporotricosis $\mathrm{N}=40$

\begin{tabular}{lcr}
\hline Procedencia & No. Pacientes & $\%$ \\
\hline Bogotá & 6 & 15,0 \\
Cundinamarca & 8 & 20,0 \\
Meta & 3 & 7,5 \\
Santander & 1 & 2,5 \\
Casanare & 1 & 2,5 \\
Arauca & 2 & 5,0 \\
Tolima & 2 & 5,0 \\
Vichada & 1 & 2,5 \\
Boyacá & 1 & 2,5 \\
Chocó & 1 & 2,5 \\
Norte de Santander & 1 & 2,5 \\
Sin determinar & & \\
procedencia & 13 & 32,5 \\
\hline
\end{tabular}

TABLA 2

\section{Ocupación de los pacientes con Esporotricosis $\mathrm{N}=40$}

\begin{tabular}{lrr}
\hline Ocupación & No. Pacientes & $\%$ \\
\hline Agricultor & 8 & 20,0 \\
Obrero & 7 & 17,5 \\
Estudiante & 10 & 25,0 \\
Militar & 2 & 5,0 \\
Ingeniero & 1 & 2,5 \\
Enfermera & 1 & 2,5 \\
Hogar & 1 & 2,5 \\
Conductor & 1 & 2,5 \\
Oficinista & 1 & 2,5 \\
Sin definir ocupación & 8 & 20,0 \\
& & \\
\hline
\end{tabular}

La forma clínica más frecuente fue la cutánea fija, en 18 pacientes $(45 \%)$, seguida de la forma linfocutánea en 17 pacientes $(42,5 \%)$; un paciente $(2,5 \%)$ presentó esporotricosis que clasificamos como pulmonar; de un paciente $(2,5 \%)$ se aisló $S$. schenckii de sangre, lo que hace presumir una forma diseminada y en 3 pacientes $(7,5 \%)$ no fue posible clasificar la forma clínica de la entidad ya que las muestras fueron remitidas con datos incompletos de la historia clínica. Las lesiones se localizaron con mayor frecuencia en los miembros superiores, 18 pacientes $(45 \%)$, seguidas por lesiones en miembros inferiores y cara, 7 pacientes $(17,5 \%)$ con cada una.

En 15 pacientes tuvimos informe de antecedentes de trauma $(37,5 \%), 2$ de ellos al tener contacto con armadillo, 2 pacientes refirieron no haber presentado traumatismo al inicio de la enfermedad y 23 pacientes no presentaron esta información. La evolución de la enfermedad fue muy variable presentándose en 7 casos una evolución menor de 30 días, 5 de éstos presentaban la forma linfocutánea, 1 la forma cutánea fija y 1 la forma diseminada; en 15 pacientes la evolución fue mayor a 90 días; de éstos, 8 pacientes presentaron la forma cutánea fija y 7 la forma linfocutánea.

\section{Diagnóstico por el Laboratorio}

El examen directo con $\mathrm{KOH}$ realizado en 12 pacientes fue negativo en todos. La inmunofluorescencia 
directa realizada en 7 de los 40 pacientes, fue positiva en 5 de ellos (71\%). El cultivo fue positivo en 35 de los 38 pacientes $(92 \%)$ en los que se realizó. De 14 pacientes con intradermorreacción, 11 dieron positivos $(78,6 \%)$. En 18 pacientes fue posible obtener muestras de suero y los resultados de la aglutinación en tubo demostraron títulos de anticuerpos en 10 de ellos (59\%), 8 con títulos de 1:8 y 2 con títulos de 1:4. Los porcentajes de positividad de las diferentes técnicas empleadas en el laboratorio están consignados en la Tabla 3.

TABLA 3

Porcentaje de positividad de las diferentes técnicas de laboratorio

\begin{tabular}{cc}
\hline Técnicas & $\begin{array}{l}\text { No. muestras/ } \% \text { Positividad } \\
\text { No.total }\end{array}$
\end{tabular}

\begin{tabular}{lcl}
\hline Cultivo & $35 / 38$ & 92 \\
Ex directo IFD & $5 / 7$ & 71 \\
$\quad$ KOH & $0 / 12$ & 0 \\
ID R & $11 / 14$ & 79 \\
Aglutinación & $10 / 17$ & 59 \\
\hline
\end{tabular}

\section{DISCUSION}

El diagnóstico de 40 casos de esporotricosis en nuestro laboratorio, en un período de 14 años, nos indica una baja casuística $(0,6 \%$ de 7.013 muestras procesadas), esto se puede explicar por el hecho de dedicarse más nuestro laboratorio al diagnóstico de la micosis sistémicas; es así como el $65 \%$ de las muestras procesadas durante este período correspondieron a esputos y líquidos cefalorraquídeos.

En relación con los pacientes, nuestros hallazgos referentes a la edad, sexo, formas clínicas, localización de la lesión y antecedentes traumáticos están de acuerdo con lo informado en la literatura colombiana $(1,2,13)$. El antecedente de traumatismo al contacto con armadillos corrobora lo encontrado por otros grupos, que refieren aparición de la esporotricosis después de trauma ocasionado por animales: armadillo, gato, iguana (14).

El aislamiento de $S$. Schenckii de líquido pleural en un paciente, hace suponer que presentaba la forma pulmonar la cual es regularmente diagnosticada en otros países $(15,16)$ pero en Colombia constituiría el primer informe. Desafortunadamente, la muestra fue remitida al laboratorio sin datos adicionales de su historia clínica, no pudiéndose correlacionar los hallazgos del laboratorio con los de la clínica.

Del paciente con un hemocultivo positivo conocemos un diagnóstico clínico de insuficiencia renal progresiva y malaria por Plasmodium falciparum, lo cual tampoco nos permite establecer el caso definitivamente como una forma diseminada de esporotricosis.

Un paciente presentó un cuadro mixto de esporotricosis y feohifomicosis con agente etiológico Cladosporium cladosporioides (identificación realizada por $\mathbf{M}$. McGeinnis); los comentarios en relación con este caso ya fueron presentados en una publicación anterior (17).

La procedencia de los pacientes $(63,4 \%)$ del Oriente del país, sólo nos señala la ubicación del laboratorio donde se realizó el diagnóstico.

Con nuestros datos comprobamos que el laboratorio es definitivo para el diagnóstico de la esporotricosis siendo el cultivo, el mejor examen disponible lo cual concuerda con lo descrito en la literatura $(1,2,11)$. Igualmente el examen directo empleando la inmunofluorescencia y la intradermorreacción presentaron gran sensibilidad $(6,8)$; por el contrario nuestros datos de la aglutinación en tubo difieren de los presentados en otros trabajos (7). Resaltamos la importancia de la comunicación del clínico con el laboratorio, para poder correlacionar mejor los hallazgos y establecer así un diagnóstico certero y oportuno.

\section{SUMMARY}

Forty cases of sporotrichosis have been diagnosed from 1976 to 1989 at the Mycology Laboratory of the Instituto Nacional de Salud. The disease was present in patients 4 to 52 years old, and 35 of $40(87.5 \%)$ were males. Fixed cutaneous and lymphocutaneous forms were predominant, $45 \%$ and $42.5 \%$ respectively. The diagnosis was established by isolation of Sporothrix schenckii in $92 \%$ of the cases. Two patients were diagnosed using direct fluorescence, skin test and tube agglutination. 


\section{AGRADECIMIENTOS}

Al doctor Fernando Ospina, por la recopilación de los datos clínicos y de laboratorio. A la doctora Angela Restrepo, por su valiosos comentarios.

\section{BIBLIOGRAFIA}

1. Velásquez JP, Restrepo A, Calle G. Experiencia de 12 años con la esporotricosis. Polimorfismo clínico de la entidad. Antioquia Médica 1976; 26 (2): 153-169.

2. Vélez H, Santamaría L, Guzmán G, Escobar M. Esporotricosis. Aspectos clínicos en 78 pacientes. Acta Med Colomb. 1984; 9 (4): 146-149.

3. Rippon JW. Medical Mycology. Second edition. Saunders Co, Philadelphia. 1982; 277-302.

4. Lynch P, Voorher JJ, Harrell R. Systemic sporotrichosis. Ann Inter Med. 1970; 73 (1): 23-30.

5. Roberts GD. The epidemiology of sporotrichosis. In the Epidemiology of Human Mycotic Diseases. Springfield, III, Charles C Thomas. 1975; 227-235.

6. Kaplan W, Ivens MS. Fluorescent antibody staining of Sporotrichum schenkii in cultures and clinical materials. J Invest Dermatol. 1960; 35 (3): 151-159.

7. Palmer DF, Kaufman L, Kaplan W, Cavallaro JJ. Serodiagnosis of mycotyc diseases. Charles C Thomas Springfiel. 1977; 140-153.
8. Toriello C, Mariat F. Estude comparée des polyosides des champignons Ceratocystis stenoceras et Sporothrix schenkii. Composition chimique et analyse immunologique Ann Microbiol (Inst Pasteur). 1974; 125A: 187-307.

9. Vélez H, Santamaría L, Guzmán G, y col. Esporotricosis. Estudio comparativo de los antígenos miceliar y levadura del $S$. schenckii mediante pruebas cutáneas. Acta Med Col. 1984; 9 (4): 150-156.

10. Roberts GD, Howard WL. The serologic diagnosis of extracutaneous sporotrichosis. Am J Clin Pathol. 1971; 56: 597 600 .

11. Karlin J, Vielsen HS. Serologic aspects of sporotrichosis. J Infect Dis. 1970; 121 (3): 316-326.

12. Campbell MC, Stewart JL. Medical Mycology Handbook. A Wyley Medical Pub. 1980; 361.

13. Mesa J, Gómez H, Giraldo B. Esporotricosis epidémica. Medicina cutánea. 1971; V: 337-340.

14. Cont-Díaz I. La esporotricosis en el Uruguay. Aspectos epidemiológicos y clínicos. An Fac Med Montevideo, 2a. época. 1981; 4 (2): 137-146.

15. Rohatgi PK. Pulmonary sporotrichosis. Southern Med J. 1980; 73 (12): 1611-1617.

16. Naimark A, Tiu S. Primary pulmonary sporotrichosis. J Can Assoc Radiol. 1979; 30: 129-130.

17. Rodríguez G, Palencia Y. Esporotricosis. Valor diagnóstico del-cuerpo asteroide. Biomédica. 1985; $5(1,2)$ : 41-46. 